\title{
Ethics Education in Allied Health: A Systematic Review of Learning Outcomes for Entry-Level Students
}

\author{
Louise K. Wiles", Carolyn M. Murray, Amy Baker, Angela Berndt, Kobie Boshoff \\ International Centre for Allied Health Evidence, Sansom Institute, School of Health Sciences, University of South Australia, Adelaide, South \\ Australia, Australia
}

\section{Email address:}

Louise.Wiles@unisa.edu.au (L. K. Wiles)

${ }^{*}$ Corresponding author

\section{To cite this article:}

Louise K. Wiles, Carolyn M. Murray, Amy Baker, Angela Berndt, Kobie Boshoff. Ethics Education in Allied Health: A Systematic Review of Learning Outcomes for Entry-Level Students. Humanities and Social Sciences. Special Issue: Ethical Sensitivity: A Multidisciplinary Approach. Vol. 4, No. 2-1, 2016, pp. 13-24. doi: 10.11648/j.hss.s.2016040201.13

Received: December 21, 2015; Accepted: December 23, 2015; Published: May 13, 2016

\begin{abstract}
The complexities of modern healthcare pose a range of ethical issues for health professionals. In preparing student health professionals for these complexities, entry-level education must go beyond exposure to ethical theory, codes and standards. The aim of this systematic review was to determine the student learning outcomes reported in peer-reviewed allied health literature following ethics training. The review method included an a priori protocol, adherence to PRISMA statement, with critical appraisal via the Critical Appraisal Checklist for an Article on an Educational Intervention and The Critical Appraisal Skills Program (CASP) Qualitative Checklist. From a total of 1237 possible records published between 1991 and 2015,11 studies of variable methodological quality met the inclusion criteria for final synthesis. Studies focused on teaching to occupational therapy, physiotherapy, pharmacy and dietetics students $(n=588)$. Heterogeneity among studies precluded metaanalysis and data were synthesised qualitatively in a narrative format. A range of outcomes measures were used in the reviewed publications including the Structure of the Observed Learning Outcomes (SOLO), Defining Issues Test (DIT), Readiness for Interprofessional Learning Scale (RIPLS), Attitudes to Health Professionals Questionnaire (AHPQ), Student Development Task Lifestyle Inventory (SDTLI) and the Socio-moral Reflection Measure-short form (SRM-SF). Other studies surveyed students at the completion of the educational intervention using free text questions or Likert scales. The pedagogical approach used was varied, including transformative, constructivist, arts-based, inter-professional, problem-based or experiential learning approaches. The findings of this review suggest that given the current body of evidence, the teaching of ethics to and for allied health students should include the delivery of ethics focused content, be intensive in nature, link theory with real-life situations and practice, and expose students to multiple views using a variety of methods such as reflection and discussion of ambiguous, controversial topics. While the exact prescription of ethics training to maximise efficacy and uptake is unknown, there is some suggestion that immediate learning outcomes may follow a dose-response pattern, providing potential for future teaching models to incorporate repeated ethics exposure support for cumulative and sustained learning.
\end{abstract}

Keywords: Entry-Level, Students, Education, Ethics, Moral, Systematic Review

\section{Introduction}

The complexities of modern healthcare pose a range of ethical issues for health professionals. While codes of ethics and professional standards provide important and necessary frameworks for practice [1], health professionals face other ethical considerations that may, at times, be beyond the governance and scope of such codes and standards. Tensions around advocacy, rationalisation of health resources, and prioritisation of competing priorities and interests have been reported across and within various health professions [2-7].

In practice, ethical decision making must be tailored to clinical situations, which requires addressing each unique, independent and individual characteristic variable. Therefore, education of student health professionals must go beyond exposure to ethical theory, codes and standards [8] to include preparation for ethical tensions that are 'everyday' and which 
reflect the individual complexities of practice [7]. This preparation includes personal engagement with applying theory in practice [9] opportunities for critical thinking, moral appraisal and prioritisation of different options during decision making [10, 11].

Methods for teaching and learning ethics reported in the literature include modules that focus on deontology and consequentialism in nursing [12], using artistic expression to promote awareness of personal values and beliefs in occupational therapy [13], embedding ethics into interprofessional education [14, 15], using vignettes [16] and scenarios with nursing students in online and face-to-face environments [17], as well as using ambiguous cases with ethical dilemmas in physiotherapy [8]. A textual evaluation of course descriptions in occupational therapy and physiotherapy programs in Canada found that programs met the professional standards for expectations of ethics curriculum but did not address the actual learning outcomes for students [18].

Opportunities for practising ethical decision making often constitute part of the 'hidden curriculum' [11] and are rarely given enough attention [12]. In addition, outcomes of curricula which focus on the teaching of ethics are difficult to extract as they may relate to personal and professional craft knowledge, rather than clearly identifiable and measurable propositional knowledge [19]. To learn more about teaching methods and learning outcomes for health professional ethics education, there is a need to systematically appraise, analyse and synthesise existing research.

Whilst traditionally used to inform health professional practice, systematic reviews are starting to grow traction in health professional education. For example, a systematic review was conducted on the use of reflection for health professional education [20] and about shared, core competencies across medicine, nursing, occupational therapy and physiotherapy [21]. Although a review has been conducted about ethical tensions in occupational therapy practice [22] and for teaching ethics in medicine [23], there have been no systematic reviews exploring the teaching and learning of ethics for students enrolled in allied health professional programs. Therefore, the aim of this systematic review was to explore the student learning outcomes reported in allied health literature following ethics training.

\section{Methods}

\subsection{Participants}

The participants of interest were entry-level allied health professional students. 'Entry-level' was defined as undergraduate and graduate entry programs that prepare students to enter their professions as beginning practitioners $[24,25]$. For the purposes of this review, the term 'allied health' incorporated the health disciplines proposed by Turnbull et al [26] with a therapy focus (i.e. nutrition and dietetics, occupational therapy, physiotherapy, podiatry, speech pathology). Excluded were those professions that were paramedical (i.e. ambulance, intensive care), may be considered alternative or complementary therapies (i.e. art and music therapy) $[27,28]$, or where ethical considerations may not be directly relevant to or transferrable across other allied health disciplines. These include the specific ethical practices required in exercise physiology for athlete development [29], the delivery of psychotherapy in psychology [30], and a range of unique complexities which characterise social work [31]. Studies which sampled more than one health discipline (but included participants from the therapy-focused disciplines of nutrition and dietetics, occupational therapy, physiotherapy, podiatry, speech pathology) were eligible for inclusion.

\subsection{Interventions}

In this review, due to the absence of a universally-agreed definition or framework for what constitutes the teaching of ethics, studies simply needed to report the inclusion of at least one 'ethical' type component as the primary focus of an educational intervention (involving entry-level allied health professional students).

\subsection{Comparison}

All studies were included irrespective of the presence or absence of control or comparator groups.

\subsection{Outcomes}

For inclusion, studies had to evaluate learning outcomes following (post- and possibly pre-) the educational intervention. The outcomes of interest could include, but were not limited to, actual (i. e. measured objectively) or self-reported measures, or participants' perceptions of knowledge, values, attitudes, morals, self-awareness, behaviours, skills, and confidence [25].

\subsection{Study Design}

Only primary studies reporting original data on learning outcomes following evaluation of an ethics focused educational intervention were included. Study designs could include randomised controlled trials, controlled trials or cohort studies (pre-post and longitudinal studies) and qualitative studies. Editorials and narrative reviews were excluded. Secondary research, such as systematic reviews of primary studies (with original data on learning outcomes evaluating ethics focused educational interventions), was not included; however, reference lists of such reviews were screened to identify potentially relevant studies.

\subsection{Search Strategy}

Nine electronic databases were searched in October 2015: A+ Education (Informit), Academic Search Premier (EbscoHost), Cumulative Index to Nursing and Allied Health Literature (CINAHL), Excerpta Medica Database (EMBASE), Education Resources Information Center (ERIC), Health Source: Nursing/academic edition 
(EbscoHost), Medical Literature Analysis and Retrieval System Online (MEDLINE), Psychology and Behavioural Sciences Collection (EbscoHost), and Scopus. The Medical Subject Headings (MeSH) database was used to formulate relevant search terms. The search strategy for one database (Medline) is presented in Appendix 1. There were no restrictions placed on publication year and where possible, all searches were limited to English and studies involving humans. The reference lists of all included studies meeting the inclusion criteria were screened (pearled) to identify additional relevant studies. An expert in the field of entrylevel education and ethical decision-making was contacted and invited to provide details of additional relevant studies (Dr Gisela Van Kessel).

\subsection{Study Selection}

Two rounds of eligibility screening were completed. Firstly, the titles and abstracts were screened for inclusion of an ethical focused educational intervention (LKW). The full text of studies were retrieved when: (a) studies were identified as potentially relevant from the title and abstract, (b) the relevance of studies was uncertain from the title and abstract, or (c) the abstract was unavailable. In the second round of screening, all full text studies were reviewed against the eligibility criteria and their reference lists screened by two sets of paired reviewers (KB, $\mathrm{AB}, \mathrm{CM}, \mathrm{AB})$. Where there was uncertainty, discussion was held with the research team to reach consensus. Full agreement was reached on all included studies.

\subsection{Data Collection Process}

Data from all included studies were independently extracted by two sets of paired reviewers using a purposedesigned data extraction sheet and instructions. Results were compared and discussed with any discrepancies between reviewers' data resolved by discussion and consensus.

\subsection{Data Items}

The following information was extracted verbatim from each included study: (1) research design; (2) health professional discipline; (3) sample size; (4) ethics focused intervention (type, content, duration and mode of delivery or format); (5) outcomes measured; and, where relevant, (6) pre- and post- intervention data for the identified outcomes (mean, standard deviation, standard error, number of students before and after intervention, effect size, $p$-value, $t$-value).

\subsection{Critical Appraisal}

All included studies were evaluated for risk of methodological bias using 'The Critical Appraisal Checklist for an Article on an Educational Intervention Tool' [32]. This tool contains 13 items evaluating the research question, study presentation and design, outcome measures and results of each study. Eleven items (items 1-9, 12 and 13) have three possible gradings: 'Yes', 'Can't Tell', and 'No'. The remaining two items (items 10 and 11) require a narrative response. For the purpose of this study, a score of one point was allocated for items that were graded 'Yes'; and zero points for 'Can't Tell', 'No' or 'Non-applicable'. This applied to all of the 11 graded items, except item 13 where 'No' indicates a positive response and was therefore allocated one point. To capture an additional aspect of methodological rigor (i.e. Has the relationship between researcher and participants been adequately considered?), one item (question 6) from 'The Critical Appraisal Skills Program (CASP) Qualitative Checklist' [33] was added to the critical appraisal process (Table 1). The authors identified this as an important factor to consider in educational intervention studies where the power differential between course administrators (i.e. lecturers and tutors) and students may influence learning outcomes, especially those of a self-reported nature. The highest possible critical appraisal score was 14 .

Table 1. Critical appraisal questions.

\begin{tabular}{ll}
\hline Critical appraisal questions \\
\hline Critical Appraisal Skills Program (CASP) \\
\hline Q6. Has the relationship between researcher and participants been \\
Critical appraisal checklist for an article on an educational intervention \\
Q1. Is there a clearly focussed question? \\
Q2. Was there a clear learning need that the intervention addressed? \\
Q3. Was there a clear description of the educational context for the \\
Q4. $\quad$ Was the precise nature of the intervention clear? \\
Q5. Was the study design chosen able to address the aims of the study? \\
Q6. Were the outcomes chosen to evaluate the intervention \\
Q7. $\quad$ Were any other explanations of the results explored by the authors? \\
Q8. Were any unanticipated outcomes explained? \\
Q9. Were any reported behavioural changes after the intervention \\
Q10. $\quad$ What to mere the results of the intervention? \\
Q11. How precise were the results? \\
Q12. Was the setting sufficiently similar to your own and/or \\
Q13. Does it require additional resources to adopt the intervention? \\
\hline
\end{tabular}

\section{Results}

\subsection{Study Selection}

Our searches identified a total of 1237 records; after duplicates were removed, we screened the title and abstract of 1218 records against the inclusion criteria, of which 1184 were excluded. Thirty-four full-text articles were assessed for eligibility and their reference lists pearled. The main reasons for exclusion of 26 of these articles were the relevance of the: research design (not primary research, narrative review) and, primary focus of the intervention (i. e. not specific or relating to ethics). Additional studies were identified through pearling $(n=2)$ and expert review $(n=1)$, resulting in eleven studies for inclusion in the final synthesis. The flow of studies through the selection process is presented by way of a modified PRISMA flowchart in Figure 1 [34]. 


\subsection{Critical Appraisal}

There was good agreement among reviewers' critical appraisal scores $(\mathrm{n}=99 / 120$ items, $80.6 \%)$, with discrepancies resolved by way of discussion and consensus by all authors. Critical appraisal scores varied among the included studies (mean 8.2, median 8, range $4-11$ ), however these did not appear to follow a systematic pattern according to publication year (Table 2). The majority of studies scored a 'Yes' for most items of 'The Critical Appraisal Checklist for an Article on an Educational Intervention Tool' (items 1-7, 12); as well as a 'Yes' for item 13 (i. e. $n=6 / 11$ included studies, 54.5\% of items) where the intervention required additional resources for adoption. However few studies ( $\mathrm{n}=4 / 11,40 \%)$ offered an explanation of unanticipated outcomes (item 8), and only one $(n=1 / 11,9 \%)$ reported behavioural changes after the intervention that were linked to measurement of other, more objective measures (item 9). In terms of adequately considering the relationship between researchers and participants (question $6 \mathrm{CASP}$ tool), only three studies $(30 \%$ of those included) scored a 'Yes'.

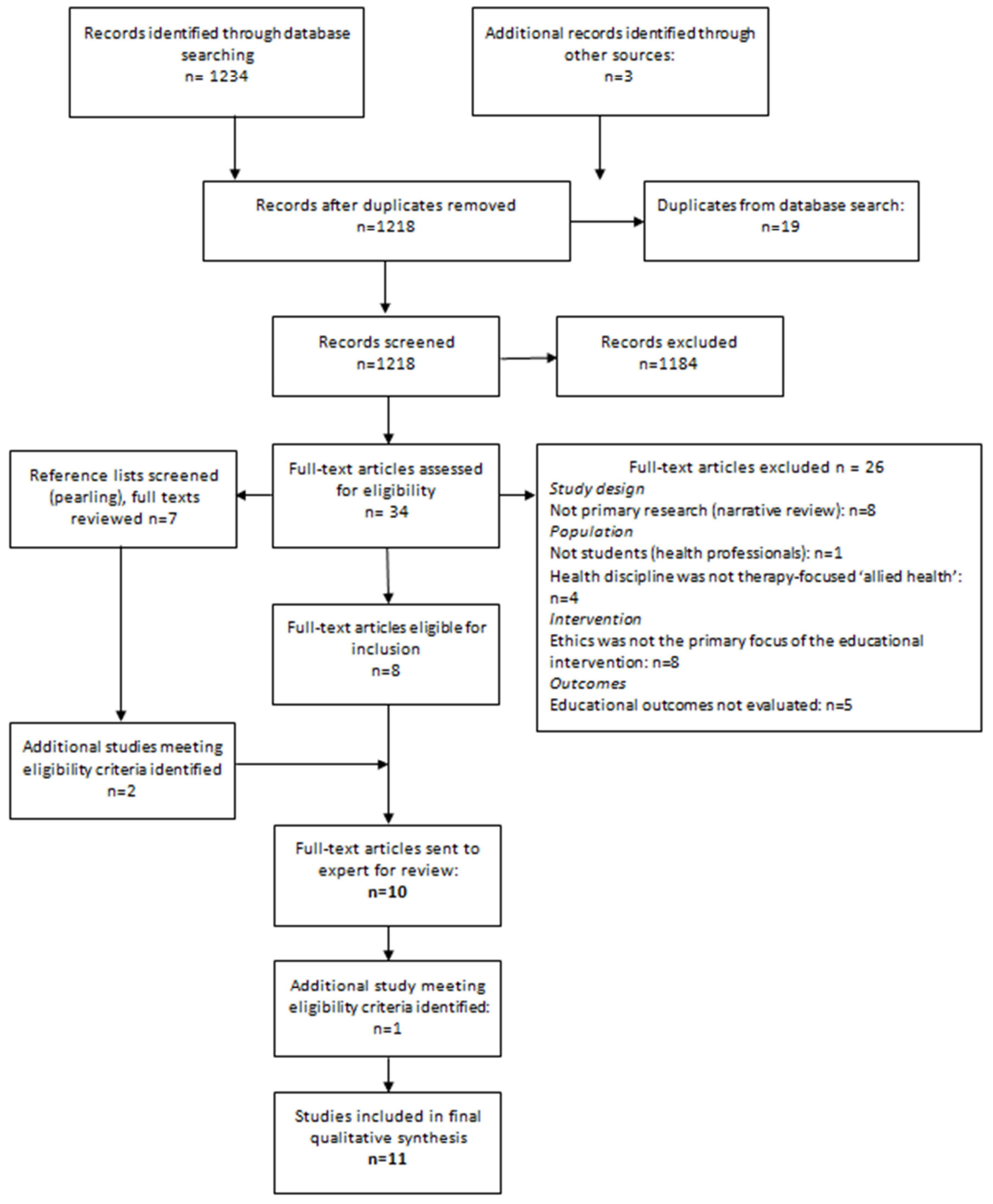

Figure 1. Modified PRISMA flowchart depicting flow of studies through the selection process [34]. 
Table 2. Summary of critical appraisal of articles on educational interventions.

\begin{tabular}{|c|c|c|c|c|c|c|c|c|c|c|c|c|c|c|c|}
\hline \multirow{3}{*}{ Study } & \multicolumn{14}{|c|}{ Question number on the critical appraisal checklist } & \multirow{3}{*}{ Total score (maximum 14) } \\
\hline & \multicolumn{2}{|c|}{ CASP } & \multicolumn{12}{|c|}{ Critical appraisal checklist for an article on an educational intervention } & \\
\hline & 6 & Score & 1 & 2 & 3 & 4 & 5 & 6 & 7 & 8 & 9 & 12 & 13 & Score & \\
\hline DeMars et al 1991 & CT & 0 & $\mathrm{Y}$ & $\mathrm{Y}$ & $\mathrm{Y}$ & $\mathrm{Y}$ & CT & CT & $\mathrm{N}$ & $\mathrm{N}$ & $\mathrm{N}$ & CT & $\mathrm{N}$ & 5 & 5 \\
\hline Greene 1997 & $\mathrm{CT}$ & 0 & $\mathrm{Y}$ & Y & $\mathrm{N}$ & $\mathrm{N}$ & $\mathrm{Y}$ & $\mathrm{Y}$ & $\mathrm{Y}$ & $\mathrm{Y}$ & $\mathrm{N}$ & Y & $\mathrm{N}$ & 8 & 8 \\
\hline Solomon \& Geddes 2000 & $\mathrm{CT}$ & 0 & $\mathrm{Y}$ & $\mathrm{Y}$ & $\mathrm{Y}$ & $\mathrm{Y}$ & $\mathrm{Y}$ & $\mathrm{Y}$ & $\mathrm{Y}$ & $\mathrm{Y}$ & $\mathrm{N}$ & $\mathrm{Y}$ & $\mathrm{N}$ & 10 & 10 \\
\hline Dieruf 2004 & $\mathrm{CT}$ & 0 & $\mathrm{Y}$ & $\mathrm{Y}$ & $\mathrm{N}$ & $\mathrm{N}$ & $\mathrm{Y}$ & $\mathrm{Y}$ & $\mathrm{Y}$ & $\mathrm{Y}$ & $\mathrm{N}$ & CT & $\mathrm{N}$ & 7 & 7 \\
\hline Whelan et al 2005 & $\mathrm{~N}$ & 0 & $\mathrm{Y}$ & $\mathrm{Y}$ & $\mathrm{Y}$ & Y & Y & $\mathrm{Y}$ & $\mathrm{N}$ & $\mathrm{N}$ & $\mathrm{N}$ & Y & $\mathrm{Y}$ & 8 & 8 \\
\hline Edwards et al 2012 & $\mathrm{Y}$ & 1 & $\mathrm{Y}$ & $\mathrm{Y}$ & $\mathrm{Y}$ & $\mathrm{Y}$ & $\mathrm{Y}$ & $\mathrm{Y}$ & $\mathrm{Y}$ & CT & $\mathrm{N}$ & $\mathrm{Y}$ & $\mathrm{Y}$ & 10 & 11 \\
\hline Swisher et al 2012 & $\mathrm{Y}$ & 1 & $\mathrm{Y}$ & $\mathrm{Y}$ & $\mathrm{Y}$ & $\mathrm{Y}$ & $\mathrm{Y}$ & $\mathrm{Y}$ & $\mathrm{Y}$ & $\mathrm{N}$ & $\mathrm{N}$ & $\mathrm{Y}$ & $\mathrm{Y}$ & 9 & 10 \\
\hline Jones et al 2014 & $\mathrm{~N}$ & $\mathrm{O}$ & $\mathrm{Y}$ & $\mathrm{Y}$ & $\mathrm{N}$ & $\mathrm{N}$ & $\mathrm{Y}$ & Y & $\mathrm{Y}$ & $\mathrm{N}$ & Y & $\mathrm{Y}$ & $\mathrm{Y}$ & 8 & 8 \\
\hline Strawbridge et al 2014 & $\mathrm{~N}$ & 0 & $\mathrm{Y}$ & $\mathrm{CT}$ & $\mathrm{Y}$ & CT & CT & $\mathrm{CT}$ & $\mathrm{N}$ & $\mathrm{N}$ & $\mathrm{N}$ & $\mathrm{Y}$ & $\mathrm{Y}$ & 4 & 4 \\
\hline Kinsella \& Bidinosti 2015 & Y & 1 & $\mathrm{Y}$ & $\mathrm{Y}$ & Y & $\mathrm{Y}$ & $\mathrm{Y}$ & $\mathrm{Y}$ & $\mathrm{N}$ & $\mathrm{N}$ & $\mathrm{N}$ & Y & $\mathrm{N}$ & 8 & 9 \\
\hline
\end{tabular}

\subsection{Study Characteristics}

The eleven included studies were published over a twentyfour year period between 1991 [35] and 2015 [13] (Table 3). There were multiple studies conducted in Australia $[8,36$, 37], Canada [13, 38, 39], and the United States of America (USA) $[10,35,40]$. Most included studies $(\mathrm{n}=8 / 11,72.7 \%)$ evaluated intradisciplinary learning outcomes for students enrolled in physiotherapy [8,36-38], occupational therapy
$[13,35,40]$ and dietetics [41] programs. However, it is important to note that three Australian studies sampled the same group of physiotherapy students [8, 36, 37] and the publications are based on the same educational program. There were three studies which recruited participants from more than one allied health discipline; combining students from physiotherapy with those from occupational therapy $[10,39]$, and pharmacy [42] programs. The characteristics of included studies are summarised in Table 3.

Table 3. Characteristics of the included studies.

\begin{tabular}{|c|c|c|c|c|c|}
\hline $\begin{array}{l}\text { Study and } \\
\text { country }\end{array}$ & Participants & Study Design & Ethics teaching intervention & Outcome measure & Learning outcomes \\
\hline $\begin{array}{l}\text { DeMars et al. } \\
1991\end{array}$ & $\begin{array}{l}\text { Occupational } \\
\text { therapy } \\
\text { students }\end{array}$ & Not reported & $\begin{array}{l}\text { Ethics content integrated throughout } \\
\text { curriculum. History and present status } \\
\text { of ethics in occupational therapy, } \\
\text { informed consent, freedom or risk, } \\
\text { brain death and quality of life, ethical } \\
\text { use of outcome measures, continuity } \\
\text { of treatment, scope of practice, } \\
\text { relationships with clients, making } \\
\text { judgements. Lectures, case studies, } \\
\text { group discussions, role play }\end{array}$ & $\begin{array}{l}\text { Student evaluation of } \\
\text { teaching modules and } \\
\text { faculty feedback }\end{array}$ & $\begin{array}{l}\text { Working knowledge of the } \\
\text { ethical principles combined } \\
\text { with the critical thinking } \\
\text { abilities needed to apply } \\
\text { these principles to dilemmas } \\
\text { in clinical practice. } \\
\text { Increased awareness and } \\
\text { sensitivity to ethical } \\
\text { concerns and complexities }\end{array}$ \\
\hline United States & $\begin{array}{l}\mathrm{N}=52 \text { total } \\
\text { Occupational } \\
\text { Therapy } \\
\text { students } \\
\text { enrolled } \\
\text { across two } \\
\text { programs } \\
(\mathrm{n}=33, \mathrm{n}=19)\end{array}$ & $\begin{array}{l}\text { Quasi- } \\
\text { experimental - } \\
\text { between group } \\
\text { and pre-test/ post- } \\
\text { test Cohort study }\end{array}$ & $\begin{array}{l}\text { Unstructured service learning, } \\
\text { applying ethics in practice. Six one- } \\
\text { hour visits to older people in nursing } \\
\text { homes }(n=19) \text { or people with } \\
\text { disabilities in the community }(n=33) \text {. } \\
\text { Reflective journaling }\end{array}$ & $\begin{array}{l}\text { Student Development } \\
\text { Task. Lifestyle Inventory } \\
\text { (SDTLI). Socio-moral } \\
\text { Reflection Measure- } \\
\text { Short Form (SRM-SF) }\end{array}$ & $\begin{array}{l}\text { The only significant change } \\
\text { was found for both groups in } \\
\text { greater self-awareness. } \\
\text { Changes were noted in } \\
\text { values of empathy, equality } \\
\text { and justice. No changes in } \\
\text { moral reasoning }\end{array}$ \\
\hline $\begin{array}{l}\text { Solomon \& } \\
\text { Geddes } 2000\end{array}$ & $\begin{array}{l}\text { Physiotherapy } \\
\text { students in } \\
\text { third semester } \\
\text { of a two-year } \\
\text { program }\end{array}$ & $\begin{array}{l}\text { Qualitative case } \\
\text { study }\end{array}$ & $\begin{array}{l}\text { Learning objectives related to access } \\
\text { and consent to treatment, and respect } \\
\text { for individual differences (assessment } \\
\text { and treatment of rheumatoid arthritis). } \\
28 \text { tutorials of ethics education } \\
\text { focusing on different problems in } \\
\text { health care (in third semester of a two- } \\
\text { year program) }\end{array}$ & $\begin{array}{l}\text { Recording of two half- } \\
\text { hour tutorials; preceded } \\
\text { by students ranking the } \\
\text { importance of specific } \\
\text { learning issues } \\
\text { (questionnaire), and } \\
\text { followed by participation } \\
\text { in focus groups two } \\
\text { weeks later (to discuss } \\
\text { learning issues). Two } \\
\text { tutors participated in } \\
\text { semi-structured } \\
\text { interviews }\end{array}$ & $\begin{array}{l}\text { The majority of students } \\
\text { seemed to recall discussion } \\
\text { of cultural issues but did not } \\
\text { describe this using ethical } \\
\text { terminology. Students and } \\
\text { tutors reported that they } \\
\text { preferred to focus on } \\
\text { rheumatoid arthritis because } \\
\text { students found ethics content } \\
\text { difficult to research for } \\
\text { learning issues and tutors } \\
\text { weren't confident to } \\
\text { facilitate discussions about } \\
\text { ethics. }\end{array}$ \\
\hline United States & $\begin{array}{l}\mathrm{N}=94 \text { total } \\
\text { Physiotherapy } \\
(\mathrm{n}=58) \text { and } \\
\text { Occupational }\end{array}$ & $\begin{array}{l}\text { Longitudinal Pre- } \\
\text { test/ post-test }\end{array}$ & $\begin{array}{l}\text { Section on ethics during first semester } \\
\text { and then units throughout curriculum. } \\
\text { Ethics in relation to practice } \\
\text { scenarios, decision making and }\end{array}$ & $\begin{array}{l}\text { Defining Issues Test } \\
\text { (DIT) on the first day of } \\
\text { class and again during } \\
\text { students' final semester. }\end{array}$ & $\begin{array}{l}\text { Analysis of covariance, Age } \\
p=0.003 \text {; profession } p=0.07 \text {, } \\
\text { time by profession } p=0.499 \text {. } \\
\text { No significant differences }\end{array}$ \\
\hline
\end{tabular}




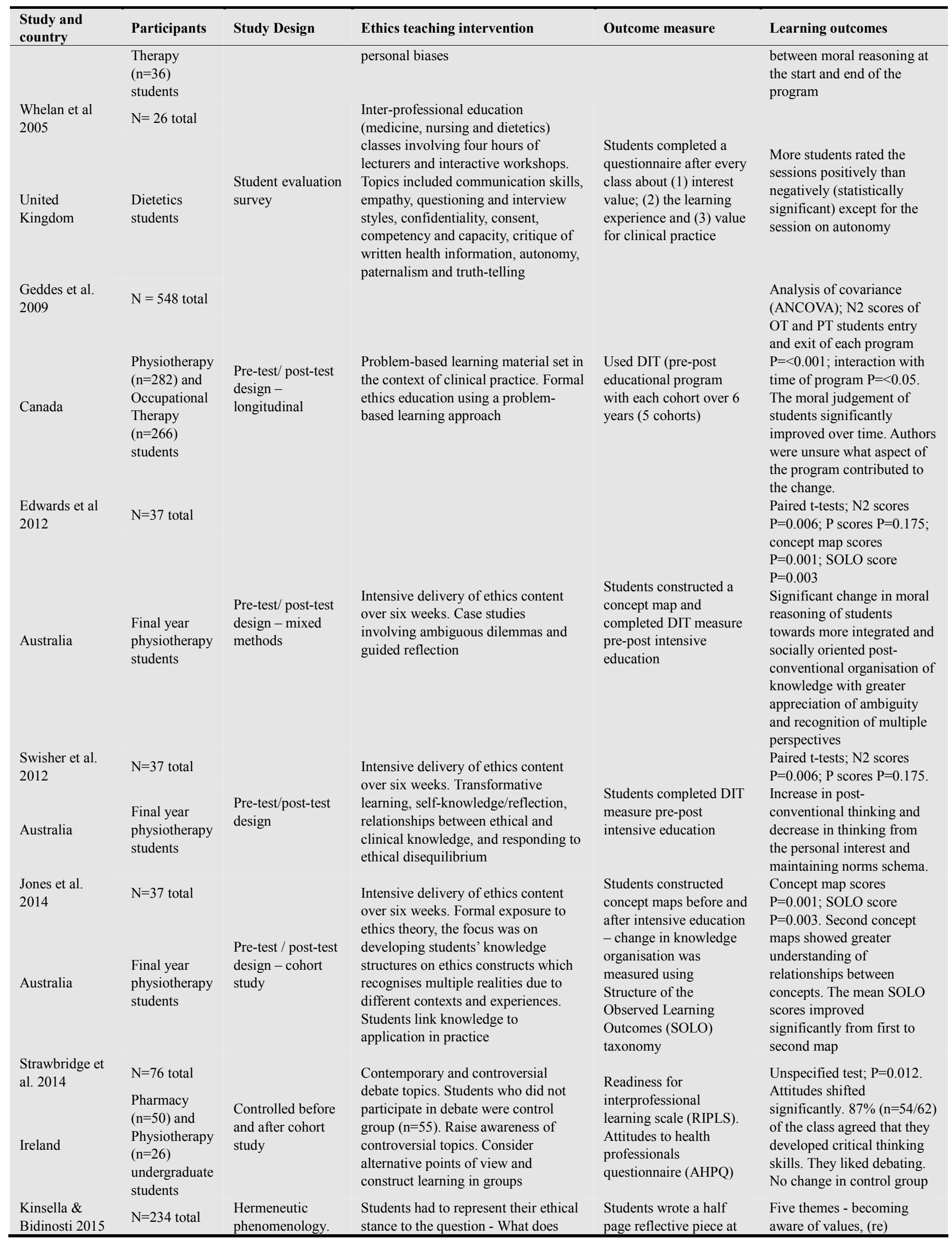




\begin{tabular}{|c|c|c|c|c|c|}
\hline $\begin{array}{l}\text { Study and } \\
\text { country }\end{array}$ & Participants & Study Design & Ethics teaching intervention & Outcome measure & Learning outcomes \\
\hline & & $\begin{array}{l}\text { Longitudinal with } \\
\text { data collected } \\
\text { over } 5 \text { years }\end{array}$ & $\begin{array}{l}\text { ethical practice mean to me? using a } \\
\text { range of artistic means; a 3-D model, } \\
\text { a piece of visual art such as a painting, } \\
\text { collage, pen and ink drawing; literary } \\
\text { works of art (poetry), a dramatic } \\
\text { performance or script, a short story. } \\
\text { Topics included ethical theories, } \\
\text { ethical principles, ethical tensions, } \\
\text { narrative ethics, ethics of care, moral } \\
\text { agency, and obstacles to moral } \\
\text { reasoning, reflective deliberation, and } \\
\text { ethically-based decision making. }\end{array}$ & $\begin{array}{l}\text { completion of the course } \\
\text { which were thematically } \\
\text { analysed }\end{array}$ & $\begin{array}{l}\text { discovering creativity, } \\
\text { coming to value reflection in } \\
\text { professional life, deepening } \\
\text { self-awareness and } \\
\text { developing capacities to } \\
\text { imagine future practices }\end{array}$ \\
\hline Canada & $\begin{array}{l}\text { Occupational } \\
\text { Therapy } \\
\text { students }\end{array}$ & & & & \\
\hline
\end{tabular}

\subsection{Synthesis of Results}

Heterogeneity among included studies precluded metaanalysis. Therefore, data were synthesised qualitatively in a narrative format, with descriptive statistics (mean, standard deviation, standard error, number of students before and after intervention, effect size, p-value, t-value) reported where available.

\subsubsection{Pedagogy and Content of Interventions}

The pedagogical approach used by educators was varied, comprising learning approaches across transformative learning [8, 13, 36, 37], constructivist [37, 42], arts-based [13], inter-professional learning [41, 42], problem-based learning [38, 39] and experiential learning [40] approaches. The remaining studies in this review did not specify a particular approach $[10,35]$. Some pedagogical approaches led to innovative methods of course content delivery, such as students constructing concept maps [8, 37], participating in debates on controversial topics [42], and creatively expressing what ethical practice means to them [13].

With the exception of Greene [40], all other studies reported specific content devoted to ethics education which was variable in its timing, intensity and mode of delivery. An ethics course for final year physiotherapy students was delivered intensively for three hours per week over six weeks, in conjunction with online activities and discussion [8, 36, 37]. Similarly, the ethics courses described by Solomon and Geddes [38] and Kinsella and Bidinosti [13] were delivered towards the end of the educational program. In contrast, two studies $[10,35]$ timed the majority of their ethics education within the first year, and further content was delivered throughout the curriculum. Two other studies also provided ethics education in the early stages of the educational program (i.e. to first year students) [41, 42] with the remaining study including ethics training throughout the overall curriculum [39]. Across studies, there was considerable variation in the content of ethics education, with most focusing on development of moral reasoning and thinking $[8,10,36,37,39]$, or ethical theory and principles $[13,38,42]$. Relatively few studies focused on professional behaviours such as communication and empathy [40,41], or used a combined approach [35].

\subsubsection{Study Design and Data Collection}

There were two qualitative studies; Solomon and Geddes [38] triangulated data collection methods through recording and analysing two tutorial sessions, asking students to rank learning issues and then discussing these in a focus group, and also conducting semi-structured interviews with two tutors. Kinsella and Bidinosti [13] used a hermeneutic phenomenological approach to gather data using textual analysis of a half page reflection written by students at the completion of their course. Seven studies reported a pre-post test design, with a variety of outcome measures used amongst these studies $[8,10,36,37,39,40,42]$. One study used a student questionnaire [41] and one did not stipulate the design used [35]; however, reported student and faculty feedback.

\subsubsection{Outcome Measures}

The Structure of the Observed Learning Outcomes (SOLO) tool was used to show change $[8,37]$ in students' knowledge organisation in their concept maps. The SOLO is a taxonomy illustrating increasing levels of structural complexity in student learning. One study also reported findings from measures on the Defining Issues Test (DIT), particularly the $\mathrm{N} 2$ and $\mathrm{P}$ scores [8]. The $\mathrm{P}$ score is an indicator of principled or post-conventional moral reasoning developed by analysis of ranked responses to six scenarios by participants in two studies [36, 39]. The N2, also a measure of post-conventional moral reasoning and considered the gold standard DIT index [36], was developed after the $\mathrm{P}$ score as a more reliable measure, as it both ranks and rates the data as seen in Swisher et al. [36] and in Rest et al. cited by Geddes et al. [39]. Post-conventional reasoning relies on ethical ideals, societal cooperation and principles of fairness, compared to personal interest that relies on one's self-interest and well-being, or maintaining norms where laws, rules, conventions and traditional sources of authority inform reasoning, pp.169 in the Swisher et al. [36].

The DIT was used in a pre-test and post-test design in three other studies $[10,36,39]$. Two studies conducted their research as controlled, cohort studies with the Strawbridge et 
al. [42] study collecting and comparing outcomes from students who participated in debates with data from students who did not participate and the Greene [40] study comparing outcomes for students involved in service learning with two different client groups (older people in nursing homes and adults with disabilities in the community).

Aside from the DIT, other outcome measures included the readiness for interprofessional learning scale (RIPLS) [42], the attitudes to health professionals questionnaire (AHPQ) [42], the lifestyle inventory (SDTLI) and the socio-moral reflection measure-short form (SRM-SF) [40]. Other studies surveyed students at the completion of the educational intervention [38] or after each class using free text questions and evaluation questions with Likert scales [41]. Similarly, the DeMars et al. [35] study evaluated learning outcomes by seeking feedback from student and faculty but this was in relation to ethics content in their whole curriculum rather than a specific course.

\subsubsection{Learning Outcomes}

Significant changes in moral judgement scores on the DIT N2 scores were noted for both groups of occupational therapy and physiotherapy students undertaking problembased learning for the whole two year curricula [39]. When the interaction of time with program was measured, there was more movement from baseline to time two for the occupational therapy students than the physiotherapy students, with occupational therapy students starting with slightly lower moral judgement scores and ending with slightly higher scores (pp. 98 in Geddes et al.) [39]. However, the results showed no differences at exit based on gender, as results were affected by low numbers of males in the occupational therapy cohort, or by previous education.

Changes in moral reasoning following a six week, final year ethics education module were reported in two articles using data from the same study which reported both N2 and $P$ scores $[8,36]$. Whilst mean changes in N2 scores for moral reasoning for physiotherapy students at time two were significant, when analysed in groups the significant change only occurred for female physiotherapy students $(n=22$; $59.5 \%$ ). There were no significant findings for the $\mathrm{P}$ score for the entire physiotherapy student group or for the males [36]. No significant differences were found on the DIT P scores in the study by Dieruf [10] when comparing occupational therapy and physiotherapy students and the two years spent studying (time), which may be attributable to the nonspecific nature of the intervention (i. e. their whole curriculum). However, Dieruf [10] did find a significant relationship between $\mathrm{P}$ scores and age of students.

Evaluation of the concept maps [8] found that students had learned constructively from the process of having to work through unsettling and ambiguous cases in groups, both in class and online. Analysis of the concept maps found a shift from uni-structural learning at time 1 (SOLO level 2) to relational learning at time 2 (SOLO level 4) $(\mathrm{P}=0.003)$, suggesting students had integrated and organised their learning and thus see how topics related to each other, holding greater meaning and relevance than prior to the educational intervention. Comparison of the SOLO level outcomes and the DIT N2 scores showed no significant correlations.

Through a descriptive evaluation of their course, Strawbridge et al. [42] reported percentages of agreement and pre- and post- $p$ values, finding the debates encouraged active learning through challenging topics (95\% agreement) and were an appropriate way to learn ethics $(87 \%$ agreement), with students also becoming more cognizant of conflicting views about topics. Through their analysis of student reflective writing, Kinsella and Bidinosti [13] found students were seeing the connections between ethical and reflective practice and had become more self-aware of their own assumptions, beliefs and values through using arts as a learning medium. In particular, changes in moral judgement can be seen in the following quote extracted from their research.

'Reflecting on this experience encouraged me to think deeply about how I felt... and how I can incorporate this [reflection] into my practice. I learned that while ethical practice is twisty and complicated I should not be intimidated because I have started to develop skills that will aid me in the future.' (Catlin), pp. 10-11 in Kinsella and Bidinosti [13].

Faculty who participated in the evaluation by DeMars et al. [35] reported that they believed students were able to consider situations from different perspectives after completing the curriculum. However, the tutors interviewed in Solomon and Geddes [38] reported facilitation of discussions about ethics to be difficult, as they had not learned much about ethics themselves and were unfamiliar with the ethical language. Students in the same study stated they preferred to focus on the condition knowledge rather than prioritise learning about ethical issues related to the condition.

"Sometimes, especially at the beginning of a problem, there are so many learning issues that we have generated. For an ethical issue, we're like, okay let's put that on the back-burner because there's so much to learn before that" (student), pp. 282 in Solomon and Geddes [38]

\section{Discussion}

Ethics training for entry-level students is important to equip them with the necessary foundation knowledge and skills for clinical practice. This systematic review is the first to explore learning outcomes for entry-level allied health students following ethics training. The eleven included studies were conducted across five westernised countries, used varied methodological approaches and reported results for a total of 1057 entry-level students enrolled in one of four allied health disciplines ( $n=588$ occupational therapy, $n=393$ physiotherapy, $n=50$ pharmacy, $n=26$ dietetics). While the findings are limited to the scope of the review question, and the methodological parameters and reporting standards of included studies, our approach was strengthened by the development of an a priori protocol and adherence to the 
PRISMA statement [34].

In keeping with existing literature, there was a predominance of single group pre- and post-test designs [43]. No studies reported outcome data in sufficient detail (e. g. mean, $\mathrm{SD}$, sample size, t-value, $\mathrm{p}$-value) to enable calculation of effect size [25]. In addition, only three studies $[8,13,36]$ adequately reported consideration of the relationship between researchers and participants. We consider this to be a sizeable omission within the context of educational research, due to the power and status differentials that exist between academic staff and their students, and the potential effects these could exert on learning participation, engagement and outcomes $[44,45]$.

Due to the heterogeneity among studies within this review, it is difficult to conclusively determine the effects of ethics education, and to tease out which characteristics are most effective [46]. However, within this sample, it appears that the teaching of ethics to allied health students is associated with improvements in a range of learning outcomes, comprising greater self-awareness [13], greater understanding of relationships between concepts [37], higher levels of sophisticated thought with respect to moral judgement [39], reasoning and post-conventional thinking $[8,36]$.

Studies reporting positive student outcomes described a specific focus on the teaching of ethics content. The deliberate delivery of ethics content within programs was specified in some studies $[13,38,39,41,42]$, as well as in the description of the ethics program in three related studies within our sample $[8,36,37]$. The educational program delivered by three studies $[8,36,37]$, stipulated that it was delivered across six weeks, with weekly three-hour face-toface sessions and online modules. In contrast, the study by Dieruf [10] - which also had a specific focus on the teaching of ethics content - found no significant differences in moral reasoning between the start and end of the program. While the exact details of program delivery were not provided, the author questioned whether the intensity of the focus on ethics content was sufficient, given that the content was delivered in one section on ethics in the first semester, followed by small units in the curriculum.

Programs with positive learning outcomes were characterised by the linking of ethics theory to real-life situations and practice, with a range of teaching methods being employed $[8,36,37,39]$. Examples of this approach included the use of problem-based learning scenarios and case studies. The teaching and assessment methods within these programs exposed students to multiple points of view, with a variety of interactive forums including debates, discussions and presentations [13, 37, 39, 41, 42]. Reflection was also used in some programs $[8,13,36,37]$. In addition, ambiguous, controversial topics were used [8, 42].

While it is beyond the scope of this review to comment on the mechanisms by which students' ethical learning outcomes improved, this was discussed within some of the included studies and appeared to differ between whole of curriculum approaches and intensive or targeted courses. The learning and teaching interventions in each of the studies varied in time and intensity, as well as explicit focus on ethics and exposure. A number of studies reported on integrated curriculum or problem-based learning, whereby the entire curriculum formed the intervention e. g. in DeMars et al. and Greene [35, 40]. The relationship of time spent at university, as described in Geddes et al. [39], versus students' age - found as a factor in the study by Dieruf [10] - conflated results of studies. In these instances, authors argued the curriculum did have an effect but speculated on the evidence that general exposure to tertiary education influences the moral development of students [47] and acknowledged that age or maturity may have a possible effect on capacity for moral development.

A review of the effect of evidence-based training for health professional students (pp. 111 in Wong et al.) [25] also found that previous educational experiences and time could have carried over to postgraduate education, resulting in higher baseline measures, leaving less scope for improvement. However, a US study of the moral reasoning development of 165 medical students, when comparing exposure to the general curriculum to experience of a course focused on ethics and professionalism, found no differences in DIT P scores $(P=0.312)$ [47]. In Murrell [47], similar to many in this review, age was not a factor. However, in contrast to other evidence, time spent at university was also not a factor with no significant progress in moral reasoning taking place in the four years of medical education, (pp. 222 in Murrell) [47]. Murrell [47] highlighted the medical students operated in the conventional level of moral processing, thinking within rules-based constructs; which in the medical professions would be reflected in professional and evidence based standards and cost limits established by hospitals. Rules-based reasoning can be described as a Maintaining Norms Schema (pp.168 in Swisher et al.) [36], where the person relies on laws, societal norms, traditions, conventions and sources of authority rather than ethical ideals or principles of fairness. It is interesting to reflect on the relationship, and possible tensions between education that assist students to reach a post-conventional level of moral reasoning, and the future contexts in which they will work. Of which, the latter may potentially favour a rules-based approach to decision making.

No study was able to specifically state what intensity or combination of core learning activities were most effective, with the range including a six-week delivery, a debate program and lecture / workshop formats. Yet the notion of the learning being constructed in a manner that fostered transformational outcomes was recommended. Studies which used focused, intensive and interactive education interventions, such as Swisher et al., Whelan et al. and Greene [36, 41, 42] presented the strongest measurable changes in outcomes, and as a result argued that intensity and targeted curriculum is a key factor to consider. A number of mechanisms were used to promote reflection and deeper understanding, including debates, concept maps or reflective journaling. Kinsella and Bidinosti [13] used an arts based intervention and measured students' learning via their reflective writing to show that students considered their 
values and reflection in professional life. In agreement with several of the methods used in studies in this review, Brody and Doukas [48], in a philosophical ethical analysis of the precepts of professionalism in medical education (as a subset of health care ethics), concluded that topics that fail to use reflection and fail to convey deep ethical and humanistic aspirations, also fail to support students to understand a robust presentation of professionalism that involves trust, commitment to patient interests and application of virtue ethics in practice.

Most studies delivered ethics training to students who were enrolled within the one allied health discipline. In clinical practice, healthcare has moved to a multidisciplinary model, therefore it is somewhat surprising that few studies in this review chose to employ interprofessional teaching approaches. Whether this was a function of opportunistic research design and sampling for convenience, resourcing constraints, or pre-determined prioritisation of intraprofessional ethics training is beyond the commentary capacity of this review. In a literature review [15] regarding the teaching of health care ethics for nursing and medical students, the author notes that an ethics curriculum should be purposefully designed to be taught as an interdisciplinary subject. Conceptualising health care ethics separately for individual professions implies that there are specific moral problems to be solved by different groups or that different professions seek different moral goods rather than all being concerned with autonomy, beneficence, or justice [15]. Interestingly, our review found studies that compared student learning between professions, for example, Geddes et al. and Strawbridge et al. [39, 42] reported little difference in outcomes between groups. Within this body of literature, it seemed that teaching strategies encouraging exposure to multiple points of view (such as debating, discussions and interprofessional learning) produced positive student learning outcomes and favourable student experience ratings.

The findings of this review suggest that given the current body of evidence, the teaching of ethics to and for allied health students should include the delivery of ethics focused content, be intensive in nature, link theory with real-life situations and practice, and expose students to multiple views using a variety of methods such as guided reflection and discussion of ambiguous, controversial topics. While the exact prescription of ethics training to maximise efficacy and uptake is unknown, there is some suggestion that immediate learning outcomes may follow a dose-response pattern, providing potential for future teaching models to incorporate repeated ethics exposure and support for cumulative and sustained learning.

The inconsistency around the teaching of ethics observed in this review highlights the need for at least national-level consensus and standardised frameworks for entry-level ethics education in allied health. We believe a lack of agreed definitions around what constitutes the teaching of ethics, its concepts and constructs may have masked the identification of ethics interventions focused around decision making. It is possible that related work in allied health could be housed within studies investigating other reasoning-type (e. g. clinical reasoning) teaching models.

As a first step towards achieving allied health agreement in ethics education, future research must adhere to carefully designed study protocols to minimise methodological bias, and include the use of control groups (which, due to ethical considerations, may need to be in the form of historical data) and multiple intervention arms to test different models, modes and intensities of ethics teaching. Longer follow-up periods are also advocated, to track how ethical performance and maturity change over time for allied health cohorts, and particularly in response to different learning and practical environments.

\section{Conclusion}

This systematic review of literature published over a 24 year period, with a focus on the learning outcomes of allied health students, following an ethics based curriculum found that to date, evidence is limited. The review revealed that ethics education is delivered using diverse content, formats and intensities, leading to difficulty determining which teaching tools, techniques or pedagogical approach is of the highest educational value. Despite the variability in research quality and varied outcomes amongst the studies, the teaching of ethics in a focused, reflective and transformational manner is advised. Issues such as age of students, previous educational exposure and suggestions that exposure to tertiary education alone may influence moral development, complicate the research topic. Further research to test a variety of learning methodologies, intensities and measures is required to evaluate learning outcomes over time. In addition, opportunities exist to explore mechanisms for the active engagement of students in ethics-based learning, application to their daily lives and to practice in clinical placements. Finally, future research opportunities should include longitudinal and follow-up study designs that explore factors which hinder or help students to maintain their ethical ideals in practice after graduation. Then, and only then, can we know that we are doing our best to equip allied health students and professionals with the tools they need to navigate the complex clinical landscape and ethical terrain that characterises a career in modern healthcare.

\section{Appendix 1. OVID Medline Search Strategy}
1. learn*
2. teach*
3. 1 or 2
4. student*
5. learner*
6. 4 or 5
7. ethic*
8. moral* $^{*}$
9. 7 or 8
10. decision-making 
11. care

12. duty

13. responsibility

14. accountability

15. experience

16. or/10-15

17. occupational therap*

18. physiotherap*

19. physical therap*

20. speech therap*

21. speech patholog*

22. podiatr*

23. diet*

24. nutrition*

25. allied health

26. or/17-25

27. 3 and 6 and 9 and 16 and 26

\section{References}

[1] B. J. Kenny, et al., Ethical perspective on quality of care: the nature of ethical dilemmas identified by new graduate and experienced speech pathologists. International journal of language \& communication disorders, 2009. 44 (4): P. 421439. doi: $10.1080 / 13682820902928711$.

[2] C. Carpenter, Moral distress in physical therapy practice. Physiotherapy theory and practice, 2010. 26 (2): P. 69-78. doi: $10.3109 / 09593980903387878$.

[3] S. J. Foye, et al., Ethical issues in rehabilitation: A qualitative analysis of dilemmas identified by occupational therapists. Topics in stroke rehabilitation, 2002. 9 (3): P. 89-101. doi: http://dx.doi.org.access.library.unisa.edu.au/10.1310/78241AE0-GFF0-KT55.

[4] C. Grönlund, et al., Feeling trapped and being torn: Physicians' narratives about ethical dilemmas in hemodialysis care that evoke a troubled conscience. BMC Medical Ethics, 2011. 12 (1): P. 8. doi: 10.1186/1472-6939-12-8.

[5] J. Holt and H. Convey, Ethical practice in nursing care. Nursing standard, 2012. 27 (13): P. 51-56. doi: http://dx.doi.org/10.7748/ns2012.11.27.13.51.c9451.

[6] T. Fortune, et al., Transition to practice in supercomplex environments: Are occupational therapy graduates adequately prepared? Australian occupational therapy journal, 2013. 60(3): P. 217-220. doi: 10.1111/1440-1630.12010.

[7] E. Kinsella, et al., Through the eyes of students: Ethical tensions in occupational therapy practice. Canadian journal of occupational therapy, 2008. 75 (3): P. 176-183. doi: $10.1177 / 000841740807500309$.

[8] I. Edwards, et al., The development of moral judgement and organisation of ethical knowledge in final year physical therapy students. Physical therapy reviews, 2012. 17 (3): P. 157 - 166. doi: 10.1179/1743288X12Y.0000000001.

[9] E. Kinsella, et al., An investigation of students' perceptions of ethical practice: engaging a reflective dialogue about ethics education in the health professions. Advances in health sciences education, 2015. 20 (3): P. 781-801. doi: 10.1007/s10459-014-9566-9.
[10] K. Dieruf, Ethical decision-making by students in physical and occupational therapy. Journal of allied health, 2004. 33(1): P. 24-30.

[11] C. Freed, et al., Professional and ethical decision-making among health science students: A call to action about critical thinking. Medical science educator, 2012. 22 (1): P. 33-36. doi: 10.1007/BF03341750.

[12] S. Parsons, et al., The teaching of health care ethics to students of nursing in the UK: A pilot study. Nursing ethics, 2001. 8(1): P. 45-56. doi: 10.1177/096973300100800106.

[13] E. Kinsella and S. Bidinosti, 'I now have a visual image in my mind and it is something I will never forget': an analysis of an arts-informed approach to health professions ethics education. Advances in health sciences education, 2015: P. 1-20. doi: 10.1007/s10459-015-9628-7.

[14] R. P. McNair, The case for educating health care students in professionalism as the core content of interprofessional education. Medical education, 2005. 39 (5): P. 456-464. doi: 10.1111/j.1365-2929.2005.02116.x.

[15] S. Hanson, Teaching health care ethics: why we should teach nursing and medical students together. Nursing ethics, 2005. 12 (2): P. 167-176 doi: 10.1191/0969733005ne773oa.

[16] P. W. Nolan and D. Markert, Ethical Reasoning Observed: a longitudinal study of nursing students. Nursing Ethics, 2002.9 (3): P. 243-258 doi: 10.1191/0969733002ne507oa.

[17] L. L. Hsu, Blended learning in ethics education: A survey of nursing students. Nursing ethics, 2011. 18 (3): P. 418-430. doi: $10.1177 / 0969733011398097$.

[18] A. Hudon, et al., What place for ethics? An overview of ethics teaching in occupational therapy and physiotherapy programs in Canada. Disability and rehabilitation, 2014. 36(9): P. 775780. doi: $10.3109 / 09638288.2013 .813082$.

[19] J. Higgs, et al., Professional practice and knowledge, in Practice knowledge and expertise in the health professions, J. Higgs and A. Titchen, Editors. 2001, ButterworthHeinemann: Oxford. P. 3-9.

[20] K. Mann, et al., Reflection and reflective practice in health professions education: a systematic review. Advances in health sciences education, 2009. 14(4): P. 595-621. doi: 10.1007/s10459-007-9090-2.

[21] S. Verma, et al., Core competencies for health Care professionals: What medicine, nursing, occupational therapy, and physiotherapy share. Journal of allied health, 2006. 35 (2): P. 109-115.

[22] K. Bushby, et al., Ethical tensions in occupational therapy practice: A scoping review. British Journal of Occupational Therapy, 2015. 78 (4): $\quad$ P. $212-221$ doi: $10.1177 / 0308022614564770$.

[23] J. Goldie, Review of ethics curricula in undergraduate medical education. Medical education, 2000. 34 (2): P. 108-119. doi: 10.1046/j.1365-2923.2000.00607.x.

[24] J. Higgs and H. Edwards, Education beginning practitioners: Challenges for health professional education. 1999, Oxford: Butterworth-Heinemann. 
[25] S. Wong, et al., Magnitude of change in outcomes following entry-level evidence-based practice training: a systematic review. International journal of medical education, 2013. 4: P. 107-114. doi: 10.5116/ijme.51a0.fd25.

[26] C. Turnbull, et al., Allied, scientific and complementary health professionals: a new model for Australian allied health. Australian health review, 2009. 33 (1): P. 27-37. doi: 10.1071/AH090027 \#sthash.XNtynr2E.dpuf.

[27] B. Berman, et al., Physicians' attitudes toward complementary or alternative medicine: A regional survey. Journal of the American Board of Family Practice, 1995. 8: P. 361-366. doi: 10.3122/jabfm.8.5.361.

[28] A. Vickers, Recent advances in complementary medicine. British medical journal, 2000. 321 (7262): P. 683-686.

[29] J. Denison and Z. Avner, Positive coaching: Ethical practices for athlete development. Quest, 2011. 63 (2): P. 209-227. doi: 10.1080/00336297.2011.10483677.

[30] J. Henretty and H. Levitt, The role of therapist self-disclosure in psychotherapy: A qualitative review. Clinical psychology review, 2010. 30 (1): P. 63-77 doi: 10.1016/j.cpr.2009.09.004.

[31] A. Pasini, How to make good choices? Ethical perspectives guiding social workers moral reasoning. Social work $\begin{array}{llll}\text { education, } & 2015: & \text { P. } & 1-10\end{array}$ 10.1080/02615479.2015.1081679.

[32] Department of General Practice at University of Glasgow. Critical appraisal checklist for an article on an educational intervention. 2006 Accessed 30th November, 2015; Available from: http://www.gla.ac.uk/media/media_64040_en.pdf.

[33] CASP international network. Critical appraisal skills programme: making sense of the evidence. 2010 Accessed 30th November 2015; Available from: http://www.caspuk.net/about-casp/.

[34] D. Moher, et al., Preferred reporting items for systematic reviews and meta-analyses: the PRISMA statement. Annals of internal medicine, 2009. 151(4): P. 264 doi: 10.1016/j.ijsu.2010.02.007.

[35] P. DeMars, et al., Ethics across the occupational therapy curriculum. The american journal of occupational therapy, 1991. 45(9): P. 782-787.doi: 10.5014/ajot.45.9.782.

[36] L. Swisher, et al., Evaluating moral reasoning outcomes in physical therapy ethics education: stage, schema, phase, and type. Physical therapy reviews, 2012. 17 (3): P. 167-175. doi: $10.1179 / 1743288 X 12 Y .0000000011$.

[37] M. Jones, et al., Cognitive maps and the structure of observed learning outcome assessment of physiotherapy students' ethical reasoning knowledge. Assessment \& evaluation in higher education, 2014. 39 (1): $\begin{array}{llll} & 1-20 & \text { doi: }\end{array}$ $10.1080 / 02602938.2013 .772951$.

[38] P. Solomon and E. L. Geddes, Influences on physiotherapy students' choices to pursue learning related to ethics in a problem-based curriculum. Physiotherapy Canada, 2000 (Fall): P. 279-285.

[39] E. L. Geddes, et al., Does moral judgement improve in occupational therapy and physiotherapy students over the course of their pre-licensure training? Learning in health \& social care, 2009. 8(2): P. 92-102. doi: 10.1111/j.14736861.2008.00205.x.

[40] D. Greene, The use of service learning in client environments To enhance ethical reasoning in students. The American journal of occupational therapy, 1997. 51 (10): P. 844-852. doi: 10.5014/ajot.51.10.844.

[41] K. Whelan, et al., Interprofessional education in undergraduate healthcare programmes: the reaction of student dietitians. Journal of human nutritian and dietetics, 2005. 18: P. 461-466. doi: 10.1111/j.1365-277X.2005.00650.x.

[42] J. Strawbridge, et al., Interprofessional ethics and professionalism debates: findings from a study involving physiotherapy and pharmacy students. Journal of interprofessional care, , 2014. 28 (1): P. 64-65 http://dx.doi.org/10.3109/13561820.2013.829423.

[43] D. A. Cook, et al., Method and reporting quality in health professions education research: a systematic review. Medical education, 2011. 45 (3): P. 227-238 doi: 10.1111/j.13652923.2010.03890.x.

[44] S. C. Kitto, et al., Quality in qualitative research. Medical journal of Australia, 2008. 188 (4): P. 243.

[45] D. Poff, Reflections on the relationship of research integrity to research ethics in publishing. Journal of academic ethics, 2010 (8): P. 259-263. doi: 10.1007/s10805-010-9126-8.

[46] J. E. Thistlethwaite, et al., The effectiveness of casebased learning in health professional education. A BEME systematic review: BEME Guide No. 23. Medical Teacher, 2012. $34 \quad$ (6): $\quad$ P. $\quad$ e421-e444. doi: 10.3109/0142159X.2012.680939.

[47] V. Murrell, The failure of medical education to develop moral reasoning in medical students. International journal of medical education, 2014. 5: P. 219-225 doi: 10.5116/ijme.547c.e2d1.

[48] H. Brody and D. Doukas, Professionalism: a framework to guide medical education. Medical education, 2014. 48: P. 980987. doi: 10.1111/medu. 12520 . 